\section{LOS CUENTOS DE CARMEN DE BURGOS PUBLICADOS EN LA ESFERA. ILUSTRACIÓN MUNDIAL (1914-1930)}

\author{
Guadalupe Arbona Abascal \\ Departamento de Filología Española III \\ Facultad de Ciencias de la Información \\ Universidad Complutense de Madrid \\ Avda. Complutense, $s / n$ \\ 28040, Madrid \\ arbona@ccinf.ucm.es
}

\section{CARMEN DE BURGOS SHORT-STORIES PUBLISHED BYLA ESFERA. ILUSTRACIÓN MUNDIAL (1914-1930)}

\begin{abstract}
This paper addresses the study of nine short-stories by Carmen de Burgos, Colombine, published in the arts magazine La Esfera. Ilustración de Madrid between 1914 and 1930. All of them have descriptive value and are written in different styles corresponding to the spaces depicted in them. This allows a classification in three groups according to the main traits of the stories. The first group is within a poetic naturalism. The second group is representative of a critical realism perspective, while the third one, more innovative, belongs in a humorous-cosmopolitan realism. All nine short-stories express a socially critical view, structurally ordered, and which reveals itself as the meaning of the texts.
\end{abstract}

KEY WORDS: Literature; press; media; Carmen de Burgos; Colombine; short-story; La Esfera. Ilustración Mundial.

En este trabajo se aborda el estudio de los nueve cuentos breves que Carmen de Burgos, Colombine', publica en la revista de arte La Esfera. Ilustración MundiaP, durante los años que van de 1914 a $1930^{3}$. El primero se titula "La jetatura" se publica en el primer año de la revista, el 20 de junio de 1914, y hace el número 25. El último que publica en esta colección está fechado el 15 de marzo de 1930 y se titula "Olor sabroso". No han sido reeditados ni recogidos en volumen, ni existe edición moderna de la obra de Carmen de Burgos que incluya ninguno de ellos. Reposan por tanto en la hemeroteca, entre las páginas de la revista ${ }^{4}$. Además de esta serie de piezas literarias, la firma de Carmen de Burgos aparece al pie de otras colaboraciones (artículos periodísticos, crónicas de guerra, etc.), se prescinde de estas piezas periodisticas para acometer el análisis de los cuentos 5 .
RESUMEN: Este trabajo aborda el estudio de nueve cuentos de Carmen de Burgos, Colombine, publicados en la revista de arte La Esfera. Ilustración Mundial entre 1914 y 1930. Todos ellos tienen un valor descriptivo y se modulan con diferentes estilos a partir de la visión del espacio. Esto permite una clasificación según los rasgos predominantes de cada uno de ellos: los primeros se enmarcan en una tendencia al naturalismo poético, los segundos son representativos de un realismo-crítico y los terceros, más innovadores, se inscriben en un realismo humorístico-cosmopolita. En todos ellos se descubre un fondo de crítica social, que se ordena en una estructura y se revela como el significado de los textos.

PALABRAS CLAVE: Literatura; prensa; medios; Carmen de Burgos; Colombine; cuentos; La Esfera. Ilustración Mundial.

Se debe señalar en primer lugar cómo la escritura narrativa de Colombine ofrece una notable capacidad de descripción espacial y de ambientes. Ya es así en los primeros cuentos que publica ${ }^{6}$, se corrobora en su recopilación de cuentos más famosa (Cuentos de Colombine ${ }^{7}$ ) y se confirma en otros relatos anteriores ${ }^{8}$ y coetáneos $^{9}$ a la colección de relatos, cuyo análisis e interpretación ocupa estas páginas. Así sucede en uno de ellos, el titulado "El kodak"10; valga como ejemplo de cómo la escritora muestra una agudeza visual y sensitiva para captar las situaciones y convertirlas en palabras. En este cuento, la protagonista -una incauta americana que se pasea por Hamburgo en plena guerra del 14- es una ficcionalización de la autora. La americana recoge con su cámara lo que ve, mientras la escritora nos cuenta, combinando visión e interpretación de lo visto. Lo que ve la americana y lo que se recoge en la máquina de 
fotos sólo puede ser contado por la pericia de un narrador que tiene ojos para los paisajes, pero también para sus pasiones y conflictos.

Más allá de este cuento, Carmen de Burgos posee una mirada penetrante y sugerente del espacio en la que se vuelca toda la inteligencia y capacidad creativa. Sus dotes de escritura artística se basan en la pintura de aquellos trazos que no son sólo el marco de la historia, sino que permiten que ésta sea posible. Es como si el espacio despertase en ella las sugerencias de creación, la invitación a la construcción artística; así el escenario del que se dota será el lugar ideal para el desarrollo de sus historias: "Siempre he procurado que mi novela fuese naturalista, aunque lleve escondida, como un alma indispensable, como un motor invisible, la poesía. Realismo en las descripciones, en el estilo, y un ideal como finalidad", dice en 1930"1. Es decir, parte de la descripción para llegar a descubrir, en el corazón de lo descrito, la poesía. Cosa que se corresponde con la dimensión vital que concede a los diferentes espacios, desde el Rodalquilar de la infancia a los espacios de sus viajes a través de los que se manifiesta una búsqueda personal y una mirada crítica sobre España, mirada de denuncia sobre lo propio que sobreviene a través de la pintura de otros espacios, culturas y sociedades.

De hecho, los Cuentos de Colombine expresan esta atención de su escritura hacia el espacio que podríamos resumir como el proceso que va desde el paisaje a la pasión y el conflicto. En ellos aparece el Madrid de la pobreza y de los trabajadores, frente al Madrid de la hipocresía de las clases altas y de los políticos, como por ejemplo en "La muerte del recuerdo", "Por las ánimas", "Ay del solo" o "Historia de carnaval"; otro espacio de esta colección es el Toledo estricto y de una falsa religiosidad que se refleja en "Triunfante"; otros espacios son el liberador y cosmopolita de París en "Aroma de pecado", la dolorosa pobreza de las buhardillas sombrías, tristes, muy dickensianas de Londres en "El último deseo"; el espacio cálido, exuberante y supersticioso de América Latina, es el marco de "El viejo ídolo" y los muy pegados a la tierra y a su fuerza telúrica en la Alcira abordada desde una concepción panteísta en "Los que no vivieron" y el espacio rural y sobrecogedor de "Madre por hija".

De un modo más maduro, pero siguiendo este acierto para captar ambientes, atmósferas y escenarios, en el conjunto de cuentos que nos ocupa, la categoria que resulta especialmente lograda es la del espacio. Y dentro de ella, el narrador se desplaza sobre lugares españoles, excepto el París de "Olor sabroso". En ellos logra pintar o bien los ambientes rurales de una España de la época, o bien un Madrid que esconde historias desconocidas y sobre la que hace descansar la autora su capacidad escudriñadora, como si los ambientes pintados necesitasen en primer lugar de ser sentidos, olidos, vistos y oídos pero cuya percepción no fuese completa hasta que nos revelasen sus secretas historias.

Colombine es, como ella misma dijo, una "naturalista" que puebla esos espacios con diferentes "yoes": "Yo soy 'naturalista romántica', variable como mis 'yoes' [...]. Me gusta todo lo bello y la libertad de hacerlo sin afiliarme a escuelas" (Núñez, 2006, 354). Así Colombine, pertrechada de su capacidad de testigo privilegiado y de su curiosidad insaciable, profundiza en las historias que le ofrecen los contextos que dan vida al cuadro. Historias muchas veces descubridoras de verdades que desmienten las apariencias, lo que implica una mirada aguda y, en todas ellas, un fondo de denuncia social que por ser una critica hecha desde el dolor, no la separa de sus figuras: "¿Mi pesar más intenso? ¿El que siempre va como espina molesta agarrado al corazón? Ver cómo se enseñorea la injusticia, sentir el malestar del dolor ajeno, saber que existen seres que padecen hambre... y ver a los pueblos resignados en su miseria"12.

"La jetatura", primero de los cuentos publicados en La Esfera ocupa dos páginas, la 16 y 17, y se ordena en torno a dos ilustraciones de Yzquierdo Durán. El primer dibujo representa una calle solitaria; en el primer plano, una casa con balcón, cubierto por un paño que se agita por el aire, da sombra para evitar el calor; en el umbral de la puerta una regadera abandonada y en la calle que se dibuja hacia el fondo, la silueta huidiza de un hombre con bastón y sombrero. La segunda ilustración del mismo autor nos ofrece la animada conversación de dos caballeros bien vestidos que en sendas butacas y al lado de una mesa con bebidas parecen comentar algo que les interesa a los dos. Uno de ellos fuma un cigarro mientras escucha las declaraciones de su contertulio que le comunica algo a juzgar por los gestos con los que está dibujado.

La primera ilustración se corresponde con fidelidad a la primera descripción del relato: 
La tarde provinciana estaba llena de sol, hornagada por aquel calor seco, polvoriento, pastoso del medio día bajo el cielo de un azul tan intenso, tan brillante que parecía una chapa de acero caliente tendida sobre la ciudad. Estaban cerradas las puertas, entornadas las ventanas, que dejaban entrever las amplias cortinas de lana morena, estremecidas a veces, por el movimiento nervioso de las manos que las retiraba al oír los pasos de tal cual raro transeúnte. Tenían algo de los espiones de Bélgica y los ajimeces moriscos, mezcla de recato y de espionaje, que hace presentir detrás de cada uno dos traviesos ojos de andaluza, parleros y curiosos. Me detuve un instante a contemplar el aspecto de la ciudad adormecida en aquella siesta febril, y vi aparecer al extremo de la calle la silueta de un hombre alto....

Colombine pinta en el inicio, con sugerente capacidad descriptiva, la siesta de un pueblo español, en una tórrida tarde de verano. Además se pinta a sí misma como testigo ("Me detuve un instante a contemplar") de lo que sucede en la ciudad -tiene que ver con la silueta de este hombre alto- que provoca los miedos y recelos de los habitantes del pueblo. Así sigue comentando el ambiente de una tarde festiva de verano: "Toda la atmósfera tenía algo de alegría, de melancolía, de ritmo y de pesantez al mismo tiempo". Con esa punta crítica sobre los ambientes burgueses ("pesantez") que no prescinde de la descripción sensorial admirativa: "Se respiraba Andalucía en aquella brisa marina, algo polvorienta y algo saturada de madreselva, magnolias y jazmines". Este ambiente que puede ser sentido se rompe, de nuevo, con la presencia de esta figura masculina: "Y la presencia de D. Juan bastó a destruir toda la armonía". A partir de este momento Colombine se interesa por descubrir quién es este personaje que atemoriza, genera hostilidad, hace palidecer a las señoras, provoca ruinas, divorcios,

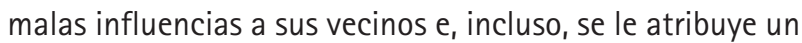
naufragio. Los descubrimientos a los que Ilega confirman el título: el enigmático don Juan, ante cuya presencia todos huyen, es un jetatura o gafe. La voz de Colombine interviene para llegar a una primera conclusión: "Era un espectáculo triste y repugnante de superstición, el de todo un pueblo acosando a aquel hombre". Solamente en el último párrafo, a través de la confesión de un personaje, se produce la revelación final que permite pasar, siempre a través de la curiosa Colombine (testigo e inquisitiva), de la acusación a todo un pueblo a su disculpa. Ahora bien, el desvelamiento final ofrece una denuncia de la pena de muerte encubierta. El don Juan, presentado como víctima de un pueblo que lo considera gafe, utilizó su oficio, el de abogado, para traicionar a unos reos y llevarlos al cadalso. La revelación final se da brevemente, en el último párrafo, y sólo quiere dejar el gusto en el lector de una traición hecha desde un puesto de responsabilidad y evocar el disgusto por la pena de muerte. Ahora bien, este descubrimiento tiene su fuerza en la sorpresa que introduce y que contradice toda la hipótesis anterior. Lo que Colombine consideraba superstición irracional parece convertirse, gracias a sus pesquisas, en intuición de la perversión de la pena de muerte y de la colaboración con ella.

El segundo cuento de esta colección se titula "Viudas de novios", se publica el 29 de mayo de 1920, en el número 334 de la revista y en su año VII. Ocupa, como en el caso anterior dos páginas -la 15 y 16-, y está ilustrado con dos dibujos firmados por Echea ${ }^{13}$. La primera ilustración representa a tres elegantes y esbeltas señoras que pasean por una calle. El segundo pinta a una niña que se empina en un cómoda para observar los tres fanales que contienen retratos y recuerdos de tres hombres jóvenes.

El relato, como en el caso anterior, vuelve a estar contado por un narrador testigo y se desarrolla en los tres momentos del cuento tradicional: una presentación para las figuras que quiere describir, un desarrollo para que el narrador nos cuente sus hábitos de vida, y un desenlace que nos revela el enigma de estas vidas. En "Viudas de novios", el narrador cuenta algo que recuerda de cuando era niña. Se trata de tres mujeres a las que admiró y con las que convivió, tres amigas de su madre -dos hermanas (Matilde y Mercedes) y una amiga (Angustias)- que viven una vida elegante, de sobria laboriosidad, atravesada por una suave melancolía. Colombine parece medirse con estas figuras que esconden un secreto y cuyas vidas le resultan enigmáticas. También se acerca a su enigma y su admiración de niña se convierte en reprobación. Parece debatirse entre ese respeto que le llevaba a pasar horas y horas con ellas de niña, tal y como se deja traslucir en su comentario, y la incomprensión hacia unas vidas que no entiende por discretas: "Había en ellas un sello de distinción melancólica, dulce y triste, que la hacía de una corrección impecable. Diríase que miraban la vida colocadas ya al margen de ella, como esos nadadores que, sentados en la orilla de un río cansados del esfuerzo, ven pasar a los que lo seguian". Se acerca a sus figuras, poniendo de manifiesto su contención, cosa que las pone en un lugar de mediocridad:

ARBOR CLXXXVI EXTRA JUNIO 2010 85-93 ISSN: 0210-1963

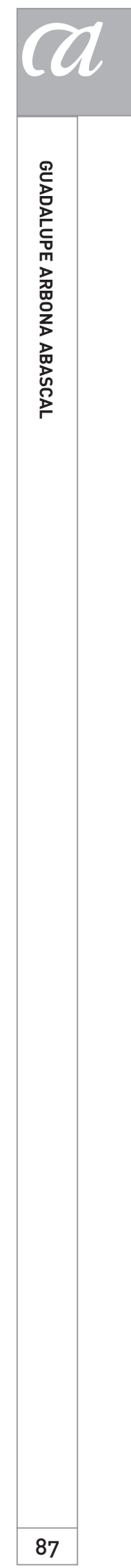


Su sonrisa afable que no llegaba a la risa; su melancolía que no llegaba a la tristeza; su complacencia que no llegaba al regocijo; sus trajes obscuros que no llegaban al luto, todo les formaba un conjunto tan ponderado, tan agradable que despertaba en mí la simpatía, y la fiesta era más fiesta en mi casa por la presencia de las tres señoras.

El desenlace del cuento que ocurre tras un salto temporal tiene carácter de revelación -interna porque el lector ya tiene la información que procura el título- y responde a la pregunta que contestan las señoras cuando la niña les pregunta por qué no han tenido hijos. Ellas responden con emoción que son "viudas de novios". A partir de este momento el desconcierto de Colombine es manifiesto ya que se balancea entre lo que considera "tres vulgares historias de amor" y entre el reconocimiento de "aquella cosa poética que había en ellas", de un cierto "aroma de azucena", de "aquella cosa de beguinaje que había en la casa".

El tercer cuento se titula "La cruz del camino". Se publica el 14 de agosto de 1920 en el número 345 de la revista del año VII. Ocupa una sola página, la número 28. Este relato posee tres partes: una descriptiva, una narrativa y una lírica; el tono es romántico y en él el narrador explícito ha desaparecido, ya no hay menciones que patenticen su presencia. Comienza, pues, siendo una descripción dolorida de lo que muestran las cruces en el camino: "Las cruces que se hallan en los caminos, cruces solitarias y siniestras, impresionan, como cruces del Via-crucis humano que muestran la última estación de alguien que debió morir a consecuencia de un asesinato o un accidente". A continuación, lo que parecía una descripción de costumbres pasa a ser relato de una de ellas y de un personaje, José Freniche, que intenta quitar una cruz de su campo para evitar las piedras que los transeúntes lanzan en señal de la petición de un sufragio por el muerto. Esta costumbre se perpetúa desde hace tres generaciones y él la intentará evitar apartando la cruz de su territorio. En el desenlace, el protagonista ve cómo lo que prometía ser una cosecha abundante se pierde porque se tiñe del rojo de las amapolas que cubre:

Llegó la primavera, las semillas entregadas a la maternidad de la tierra iban a dar sus espigas...; pero toda la extensión se cubrió de amapolas rojas. Era como si el arado al rascar en donde debía reposar el muerto, le hubiese hecho una enorme sangría. No podia, no, no labrarse la tierra que era suya. José Freniche, atemorizado y vencido, volvió a colocar en su sitio la cruz del camino.

El cuarto cuento se titula "La boda del portero". Se publica el 19 de marzo de 1921 (número 376 del año VIII de la revista). Ocupa las páginas 8 y 9 y el texto está ilustrado por dos dibujos de Echea: el primero es la figura de un portero alto y con barba, el segundo representa tres criadas que murmuran. El relato es un cuadro de costumbres que nos ofrece la historia, narrada en tres partes, de Sebastián, portero de una casa de vecinos. Primero se nos cuenta la vida feliz del portero y de su hacendosa mujer, Margarita. En segundo lugar, se presenta el enviudamiento de Sebastián y el asalto de todas las criadas de la casa que desean la portería y ocupar el puesto de la hacendosa portera. Todas ellas cambian para intentar conquistar a Sebastián. "Por instinto comprendian que para un viudo era más práctico conquistar con la seriedad". Así todas las criadas se hacen hacendosas, primorosas, cuidadosas y presumidas. Compiten por llamar la atención del portero. Colombine logra pintar el ambiente de las labores de las cocinas, los paseos y los recados: "Las muchachas tenian buen cuidado de que estuviesen las cocinas limpias y de mudar todas las semanas los papeles de los vasares, sobre todo, a primero de mes, cuando iba a subir los recibos". En la tercera parte se cuenta el desenlace que, como en el caso del cuento "Viudas de novios", está anunciado en el título. En efecto, el portero se casa y no con ninguna de las criadas sino con una desconocida. Se describe la boda: "todas se asomaron a los balcones cuando llegó la comitiva, de vuelta de la iglesia, en aquel landó de faroles blancos, con el cochero de librea, que llevaba una gran fusta adornada de flores de azahar [...] la hubieran querido matar con sus ojos al verla salir del coche, ligera y pizpireta, con su traje negro y su hermosa mantilla de encaje". Tras el casamiento se desatan las envidias y las murmuraciones en torno a la nueva portera; pero por no hallar falta en ella, las muchachas van desfilando y abandonando la casa.

"El finado" se publica el 19 de noviembre de 1921, en el número 411 del año VIII de la revista. El cuento ocupa solamente una página, la 7, y está acompañado por dos ilustraciones de Echea, menos elaboradas que las anteriores. La primera representa a una mujer llorando que está siendo consolada por otras tres $y$, tras ellas, en un segundo plano aparece un ataúd con una corona mortuoria y un cirio encendido. La segunda ilustración representa 
un hombre bien vestido, fumando un puro, sentado en una mesa y recibiendo los arrumacos y caricias de una señorita. Como se puede imaginar, el orden de las imágenes es secuencial y nos revela parte del argumento. La estructura del cuento se ordena, como el anterior, en torno a esas tres partes de la que dan razón las preceptivas clásicas, es decir, planteamiento, nudo y desenlace. En el planteamiento se describe la muerte de don Joaquín y la pena de su mujer, Adelita, que había sido feliz con él. En el nudo se nos descubre el desengaño de Adelita que, tras la muerte de su marido y guardando luto por su ausencia, se entera de su ruina económica: "había vivido engañada durante veinte años. Su marido pasaba los días en alegres meriendas con sus amigas, mujeres de las más alegres de Madrid; sostenía con el mismo lujo que ella gastaba otras tres o cuatro casas, y sus viajes eran siempre acompañado de alguna muchacha bonita". Tras este conocimiento de la traición y el desengaño, cabría preguntarse si es posible un desenlace. Sí, Colombine como en casos anteriores, guarda el acontecimiento central (Arbona, 2008, 11-73) para el desenlace del relato. Además en este caso, coincide con la decodificación del título, porque Adelita, tras el desengaño, decide cambiar su vida y no volver a referirse a su marido como el "Joaquín de su alma"; "se limitaba a decir con el tono más despectivo posible: el finado. Era la palabra que daba más exacta idea del fin de todo; de cómo había desaparecido para siempre, el difunto; de cómo había dejado de ser por completo. Nunca lo volvió a designar más que con esas dos palabras: el finado". Es decir, la máxima ignominia coincide con el olvido.

"¡Ya lo decía ella!" es el titulo de sexto cuento. Se publica el 17 de mayo de 1924 en el número 541 del año XI de la revista y ocupa una sola página. Tiene dos ilustraciones de Echea ${ }^{14}$. La primera hace referencia al oficio del protagonista -Joaquín es albañil- y nos da la imagen de dos albañiles descansando sentados en un andamio. La segunda ilustración remite al desenlace y presenta a un hombre a punto de entrar en una casa que tiene la puerta entreabierta con algo punzante en la mano.

La obra es de singular actualidad porque es el relato de un caso doloroso de maltrato. Joaquín al poco tiempo de casarse, comienza a maltratar a Soledad y ella acepta conniventemente la violencia; es más, la aumenta. Los protagonistas van involucionando a lo largo de la obra y se los describe como auténticos animales. La obra es dolorosa y el final terrible porque se acaba cumpliendo la profecía de ella, de ahí el título. Recurso que, como ya se ha visto, utiliza Colombine en estos cuentos. Soledad es asesinada por su marido, cuando éste vuelve borracho de madrugada y así se cumple el maleficio de ella que pronostica la cárcel de su marido. Como contrapunto a este cuadro de violencia doméstica, Colombine pinta dos figuras ancianas: la tía Frasca, madre de Soledad, y un compañero de Joaquín, un albañil viejo que tiene alma de niño y ama el trabajo. A la madre de Soledad se la describe así: "La pobre tía Frasca, tan respetada y sensata, no pudo sufrir las palabrotas y los escándalos del yerno, que llegó a abofetearla, y se murió días antes de nacerle el primer nieto". Las dos figuras sirven de contrapeso a la violencia de los jóvenes y hacen más dramáticas las instintividades crueles y violentas de los primeros.

"Las mejores clientes" se publica el 6 de julio de 1929, en el número 809 del año XVI. Ocupa dos páginas 18 y 19. Los dibujos de Varela de Seijas ofrecen dos figuras femeninas que conversan frente a un espejo en lo que puede ser la sala de espera de una peluquería en la primera página. El segundo es la imagen de un peluquero con unas tenacillas en la mano dispuesto a comenzar sus trabajos en la cabeza de una señora muy belle époque. En este relato se refleja con humor una descripción magnífica de la nueva técnica de las mujeres para arreglarse el pelo: la permanente. En la segunda, el narrador anónimo que daba la visión de la peluquería se personaliza: la que cuenta es clienta y clienta antigua del peluquero M. Ford. De este modo, se nos revela la historia y los méritos del peluquero checoslovaco, discipulo del famoso M. Marcel e "ilustre inventor" del ondulado en París. Colombine nos describe su incansable actividad, su técnica de los implantes capilares, etc., para después descender a la confidencia del peluquero que esa mañana muestra un aspecto triste y preocupado. Una confidencia que nos desvela el sentido del título, como sucedía en cuentos anteriores. M. Ford ha perdido a sus mejores clientas porque ha visto, sin quererlo, cómo una de ellas traicionaba a una de sus amigas con su marido. Colombine denuncia la tiranía de la que se llama "buena sociedad", que puede acabar con el modo de vida de un laborioso trabajador.

"La cuentahistorias" se publica el 8 de febrero de 1930 en el número 840 de la revista del año XVII. Ocupa las páginas 14 y 15. En la primera página aparece el dibujo de una 
anciana contando cuentos a dos niñas. El dibujo muestra en el atuendo de las niñas la moda del momento y aparece encerrado en un hexágono. El segundo ofrece la imagen de la misma anciana saliendo de una cueva excavada en la piedra. La mirada sonriente del primer dibujo se convierte en disgusto y hosquedad en el segundo. Están firmados por Quesada Hoyos. El relato cuenta la historia de una anciana recadera, rezadora y contadora de historias, la tía Ramona, a la que se describe como una mujer sin años, miserable y pobre. Vive en un agujero en el monte y es bien recibida por los niños porque sabe recitar y dar vida a los cuentos. Se describe, evocativamente el repertorio de la recitadora: ("Los duendes del castillo", "Las tres toronjas", "El espejo encantado", "El pastor que fue a misa...", "La niña a la que pegaba la madrastra y le salió una estrella de oro en la frente..."). Su pericia en el contar se mide por la utilización apropiada de los exordios del cuento tradicional ("Pues señor: una vez había...", "Este era un rey...", "Érase que se era, un padre...). Bromea con su fiel auditorio, cuando da por acabado un cuento sin permitir el gusto de la narración, una forma tradicional de avivar el interés y generar la expectación ("Pues, señor esto era un rey que tenía tres hijas; las metió en una canasta y con esto basta"). Como también conoce las formas conclusivas de la transmisión oral del cuento ("Se acabó mi cuento / con pan y pimiento / y rábanos tuertos, / y un grano de sal / pa que no haga mal"; "A mí me dieron lindos zapatos de sebo y salvao. Vino el sol, y me derritió el sebo; vino el viento, y se llevó el salvao.... colorín, colorao... este cuento se ha acabao"). La vida de la anciana son los cuentos y por eso no necesita nada más: le basta su cueva con un jergón, un candil y un cantarillo. Y su desgracia sucede cuando el cuento es tan veraz que, ajustándose al efecto teorizado y realizado por Poe, se hace verdad. Así, mientras cuenta a través de un extraordinario lenguaje no verbal cómo Satanás se lleva un niño, en ese preciso instante muere uno de los atentos infantes que siguen sus cuentos. Tras la tragedia, el destino de la tía Ramona, que vive por y de sus cuentos, es dejarse morir.

"Olor sabroso" es el último de los relatos de Carmen de Burgos en La Esfera. Sale publicado en las páginas 34 y 35 del número 845 de la revista el 15 de marzo de 1930, en el año XVIII. Está ilustrado por dos dibujos muy modernistas de Varela de Seijas. El primero representa una calle de París en la que sólo se disciernen los paraguas y las piernas esbeltas de las viandantes. Sobre el dibujo de la calle, una carta de restaurante en la que se distingue un menú escrito en francés. El título del cuento se dibuja con letras descolocadas sobre un toldo que cubre el local. En la segunda página, se perfilan las siluetas de dos señores que son atendidos por un camarero en la mesa de un restaurante.

El título alude a un olor que sale de un restaurante y que hace las delicias de Manuel y Emilio, dos españoles en Paris. El olor les hace entrar en el local a pesar de las advertencias de un señor que, haciéndose el encontradizo, les recomienda que no entren y les describe sórdidamente lo que van a hallar: los entremeses son extraordinariamente malos, la sopa y el consomé están hechos con huesos roídos, la carne es de caballo o ya usada, el pescado da urticaria, los huevos están pochos y hechos con aceite de cacahuetes, los postres prometidos no se ofrecen y los platos no se friegan. Los dos españoles entran en el restaurante a pesar de las recomendaciones porque, mientras escuchan las advertencias, perciben un "olor delicioso", "un suave aroma", como "si se masticaran de antemano los manjares", "volvió a acariciarlos el olor delicioso", "un airecillo que parecía salir de la pared". El narrador insiste en la percepción olfativa que invita, persuadiendo, a entrar. Ahora bien, cuando los personajes piden la comida todo es decepción. Deciden cambiar de restaurante y en el de enfrente, se encuentran al personaje de las advertencias que ahora les revela su secreto. Un secreto que, de nuevo, coincide con la decodificación del título y que consiste en un eficaz reclamo publicitario. Este personaje es el responsable de lo que atrae a la gente, de ese olorcillo apetitoso que, según explica, "es debido a un fuelle de mi invención que va desde el fogón a la calle para que los transeúntes perciban el olor de comidas que luego no encuentran, porque sale de un caldo inventado por mi". De este modo, presume de su base cientifica: "el perfume de los ingredientes, cuidadosamente escogidos, que forman mi caldo, hiere los nervios olfativos y la idea que recibe el cerebro ejerce su influencia sobre la secreción de la insulina, y de los jugos psíquicos del estómago. Esto provoca un apetito irresistible, imperioso: no hay más remedio que entrar y comer".

A lo largo de este repaso de los cuentos se puede llegar a las siguientes conclusiones:

1. La principal consideración es el valor documental y descriptivo de los cuentos, cuyo antecedente está presente 
en los primeros relatos de la autora, especialmente en los Cuentos de Colombine. En los cuentos breves del repertorio que he revisado, los espacios descritos a los que se acerca la Colombine testigo enmarcan las pasiones, dicen de los personajes, nos desvelan su poesía.

2. Además, se puede percibir cómo el estilo se ha depurado y se ajusta más a lo que se quiere describir, se hace más preciso sin renunciar nunca a ese valor poético que nutre cada historia y los argumentos se tensan hacia una finalidad. Como dice Concepción Núñez, se consolida "un lenguaje alejado de todo exceso, marcado por la sobriedad y la precisión y en el que las imágenes tiene un valor más iluminador que embellecedor" (Núñez, 2006, 354).

3. Se pueden clasificar los cuentos de este conjunto en tres tipos: aquellos que se ajustan a un naturalismo poético, casi una nueva forma de costumbrismo ("Viudas de novios", "La cruz del camino", "La boda del portero" y "La cuentahistorias"); los segundos, que se inclinan hacia un realismo de crítica social ("La jetatura", "El finado", "jYa lo decía ella!"); y los terceros, que se escriben desde un realismo humorísticocosmopolita ("Las mejores clientes" y "Olor sabroso"). Estos últimos se imbrican en el vanguardismo que descubre el valor del humor: "La autora defiende por medio de un personaje la función demoledora y subversiva de la risa: 'El cañón moderno es la caricatura y el humorismo la metralla'" (Núñez, 2006, 357).

4. En cuanto a la factura narrativa, nos encontramos la presencia de un narrador ficcionalizado en testigo en varios de ellos ("La jetatura", "Viudas de novios", "Las mejores clientes"). Una estructura tripartita que se ajusta a las preceptivas tradicionales del cuento en planteamiento, nudo y desenlace; y, por fin, formas novedosas de finales reveladores que pueden adquirir la forma de la negación del planteamiento ("La jetatura", "La cruz del camino"), un efecto sorprendente ("La cuenta historias" y "¡Ya lo decía ella!"), el descubrimiento de algo que se viene a conocer en el curso de la narración ("Viudas de novios", "La boda del portero") o la presencia de un elemento poético que no se preveía, como las amapolas que enrojecen el campo de José Freniche en "La cruz del camino".

5. En todos ellos se descubre un fondo de crítica social, que queda contenido en el significado del cuento y sirve de andamiaje para la organización y estructura del texto. La pena de muerte, la violencia doméstica, la traición matrimonial, la falsa religiosidad o la hipocresía de las clases altas son algunas de las dolorosas fallas que Colombine percibe en su mundo, en sus mundos.

\section{NOTAS}

1 El sentido del seudónimo ha sido estudiado por Concepción Núñez (1989, 16 y 2005, 103 y ss.). Dada la aceptación gustosa de la autora de este seudónimo en su carácter de multisignificación y su particular vinculación con los cuentos, usaré el seudónimo como sinónimo de narrador. Colombine se entiende como seudónimo que hace referencia a la labor del narrador que construye el cuento y testigo que se personaliza en la narración.

Recibido: 14 de mayo de 2010

Aceptado: 7 de junio de 2010
2 La Esfera. Ilustración Mundial es una revista que perteneció a un nuevo trust del periodismo madrileño dedicado a la publicación de revistas gráficas. Se constituyó como Prensa Gráfica S.A. y estaba controlado por Papelera Española. A la empresa pertenecian, además de La Esfera. Ilustración Mundial, otras revistas: Nuevo Mundo, Mundo Gráfico y Por esos Mundos. El grupo compitió con Prensa Española, que había integrado la revista Blanco y Negro de Luca de Tena desde 1909 (Seoane y Saiz, 1996, 308-309). La revista de lujo de este nuevo grupo fue La Esfera. El director fue Francisco Verdugo Landi y el gerente Mariano Zavala. En agosto 
de 1914 la tirada asciende a 55.000 ejemplares, costaba 50 céntimos el ejemplar. En 1917 pasa a costar 60 céntimos y una peseta en 1920, ascendiendo la tirada a 60.000 ejemplares. Según ha estudiado Florencia Friera, era una revista cara en comparación con revistas similares que se editaban en Europa. La calidad del diseño, ilustraciones, fotografías, etc. era excelente. Además de la riqueza gráfica colaboraron en ella escritores de la época como los hermanos Quintero, Emilia Pardo Bazán, José M. ${ }^{\text {C Ca- }}$ rretero ("El Caballero Audaz"), José Francés, Jacinto Benavente, Armando Palacio Valdés, Mariano de Cavia, Pérez de Ayala, Ramón Gómez de la Serna, Carmen de Burgos, Colombine, Eduardo Zamacois y Luis Bello, entre otros. Mantuvo a lo largo de su trayectoria espacios dedicados a la publicación de breves relatos.

3 La bibliografía en la que se consigna esta serie de cuentos es la de Concepción Núñez Rey (2005, 633-634). No aparecen los cuentos en la edición de 1989 de la misma crítica (1989, 38 y ss.).

4 Afortunadamente todos los números de la revista se hallan digitalizados en la Biblioteca Nacional de España y se pueden consultar en soporte electrónico (www.bne.es).

5 Joaquín Marco ha visto esta serie de crónicas sobre la Primera Guerra Mundial y dice asi: "Para La Esfera redacta crónicas de la Primera Guerra, desde una posición claramente aliadófila" (1989, 12).

6 Burgos, Carmen de (1900): Ensayos literarios, Almeria. Contiene los siguientes cuentos: "El repatriado", "Zahara", "Salud de los enfermos", "Una venganza", "La flor del valle", "Las almas hermanas", "Dos madres"; Burgos, Carmen de (1905): Alucina- ción, Madrid, Viuda de Rodríguez Sierra. Contiene los siguientes cuentos: "¿Alucinación o telepatía?", "La flor del brezo", "El último encargo", "Puñaladas mortales", "iSacrificio!", "La tiple", "ilmposible!".

7 Burgos, Carmen de (1908): Cuentos de Colombine, Valencia: Sempere.

8 Burgos, Carmen de (1909): "Amor de esposa", "¡Veinte años!", "En la paz del campo" en Los inadaptados, Valencia: Sempere; Burgos, Carmen de (1912): "Viaje sentimental", Por esos mundos, n. 208; De Burgos, Carmen (1913): "El 3.330", Nuevo Mundo, n. 1039.

9 Burgos, Carmen de (1914): "El asesino", Mundial Magazine, n. ${ }^{\circ} 40$; Burgos, Carmen de (1917): "El Kodak" en Nuevo Mundo, n. 1220.

10 Burgos, Carmen de (1917): "El Kodak", Nuevo Mundo, n. 1220.

11 Burgos, Carmen de (1930): "Prólogo" a Vida y milagros del pícaro Andresillo Pérez, La Novela de Hoy, año IX, n. 450.

12 Burgos, Carmen de (1914): "Autobiografía", Al balcón, Valencia, Sempere, p. XII.

13 Es el seudónimo de Enrique Martínez Echevarria, tal y como ha señalado Juan Miguel Sánchez Vigil (1995, 177). Ilustra cuatro de los nueve cuentos que ofrece esta colección.

14 En este número de la revista, como en los tres siguientes en los que colabora Carmen de Burgos, se aprecia un notable cambio, las páginas dejan de estar ornamentadas en los márgenes y los ilustradores se ajustan a la moda modernista, siguiendo la moda de figuras femeninas esbeltas y estilizadas de Penagos.

\section{BIBLIOGRAFÍA}

Arbona Abascal, Guadalupe (2008): El acontecimiento como categoría del cuento contemporáneo. Las historias de José Jiménez Lozano, Madrid, Arco Libros.

Burgos, Carmen de (1900): Ensayos literarios, Almería.

Burgos, Carmen de (1905): Alucinación, Madrid, Viuda de Rodríguez Sierra.

Burgos, Carmen de (1908): Cuentos de Colombine, Valencia, Sempere.

Burgos, Carmen de (1909): "Amor de esposa", "iVeinte años!", "En la paz del campo" en Los inadaptados, Valencia, Sempere.

Burgos, Carmen de (1912): "Viaje sentimental", Por esos mundos, n. 208.

Burgos, Carmen de (1913): "El 3.330" en Nuevo Mundo, n. 1039.

Burgos, Carmen de (1914): "La Jetatura", La Esfera: Ilustración Mundial, Año I, n. 25,20 de junio, pp. 16 y 17.

Burgos, Carmen de (1914): "El asesino", Mundial Magazine, n. ${ }^{\circ} 40$.

Burgos, Carmen de (1917): "El Kodak", Nuevo Mundo, n. 1220.

Burgos, Carmen de (1920): "Viudas de novios", La Esfera: Ilustración Mundial, Año VII, n. ${ }^{\circ} 334,29$ de mayo, pp. 15 y 16.

Burgos, Carmen de (1920): "La cruz del camino", La Esfera: Ilustración Mundial, Año VII, n. ${ }^{\circ} 345,14$ de agosto, p. 28.

Burgos, Carmen de (1921): "La boda del portero", La Esfera: Ilustración Mundial, Año VIII, n. ${ }^{\circ} 376,19$ de marzo de 1921, pp. 8 y 9.

Burgos, Carmen de (1921): "El finado", La Esfera: Ilustración Mundial, Año VIII, n. ${ }^{\circ} 411,19$ de noviembre, p. 7.

Burgos, Carmen de (1924): "¡Ya lo decía ella!", La Esfera: Ilustración Mundial, Año IX, n. ${ }^{\circ}$ 541, 17 de mayo, p. 11.

Burgos, Carmen de (1929): "Las mejores clientes", La Esfera: Ilustración Mundial, Año XVI, n. ${ }^{\circ} 809,6$ de julio, pp. 18 y 19.

Burgos, Carmen de (1930): "La cuentahistorias", La Esfera: Ilustración Mundial, 
Año XVII, n. ${ }^{\circ} 840,8$ de febrero, pp. 14 y 15.

Burgos, Carmen de (1930): "Olor sabroso", La Esfera: Ilustración Mundial, Año XVII, n. ${ }^{\circ}$ 845, 15 de marzo, pp. 34-35. Burgos, Carmen de (1930): "Prólogo" a Vida y milagros del pícaro Andresillo Pérez, La Novela de Hoy, año IX, n. 450.

Burgos, Carmen de (1989): La flor de la playa y otras novelas cortas, Madrid, Castalia. Introducción de Concepción Núñez Rey (pp. 9-79).
Burgos, Carmen de (1989): Los anticuarios, Madrid, Biblioteca Nueva. Prólogo de José María Marco.

Friera Suárez, Florencio (1986): Artículos y ensayos en los Semanarios España, Nuevo Mundo y La Esfera, Oviedo, Servicio de Publicaciones de la Universidad de Oviedo.

Núñez Rey, Concepción (2005): Colombine en la Edad de Plata de la literatura española, Sevilla, Fundación José Manuel Lara.
Núñez Rey, Concepción (2006): "La narrativa de Carmen de Burgos, Colombine, el universo humano y los lenguajes", Arbor Ciencia, Pensamiento y Cultura, CLXXXII 719 mayo-junio, pp. 347-361.

Sánchez Vigil, Juan Miguel (1995): La documentación fotográfica en España:Revista la Esfera (1914-1920). Tesis doctoral de la UCM dirigida por José López Yepes.

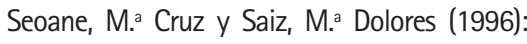
Historia del periodismo en España. El siglo XX: 1898-1936, Madrid, Alianza Editorial. 